\title{
Tribological performance of novel nickel-based composite coatings with lubricant particles
}

\author{
Ignacio TUDELA ${ }^{1, *}$, Andrew J. COBLEY ${ }^{2}$, Yi ZHANG ${ }^{1, *}$ \\ ${ }^{1}$ Daido Metal Co., Ltd. European Technical Centre UK, Research \& Development Department, Winterhay lane, Ilminster TA19 9PH, United \\ Kingdom \\ ${ }^{2}$ Functional Materials Research, Centre for Manufacturing and Materials Engineering, Faculty of Engineering, Environment and Computing, \\ Coventry University, Priory Street, Coventry CV1 5FB, United Kingdom
}

Received: 13 August 2017 / Revised: 28 November 2017 / Accepted: 06 February 2017

C The author(s) 2018. This article is published with open access at Springerlink.com

\begin{abstract}
The present study is focused on the evaluation of the tribological performance of novel Ni/hBN and $\mathrm{Ni} / \mathrm{WS}_{2}$ composite coatings electrodeposited from an additive-free Watts bath with the assistance of ultrasound. Lubricated and non-lubricated scratch tests were performed on both novel composite coatings and on standard $\mathrm{Ni}$ deposits used as a benchmark coating to have an initial idea of the effect of the presence of particles within the Ni matrix. Under lubricated conditions, the performance of the $\mathrm{Ni} / \mathrm{hBN}$ composite coating was very similar to the benchmark $\mathrm{Ni}$ coating, whereas the $\mathrm{Ni} / \mathrm{WS}_{2}$ behaved quite differently, as the latter did not only show a lower coefficient of friction, but also prevented the occurrence of stick-slip motion that was clearly observed in the other coatings. Under non-lubricated conditions, whereas the tribological performance of the Ni/hBN composite coating was again very similar to that of the benchmark $\mathrm{Ni}$ coating, the $\mathrm{Ni} / \mathrm{WS}_{2}$ composite coatings again showed a remarkable enhancement, as the incorporation of the $\mathrm{WS}_{2}$ particles into the Ni coating not only resulted in a lower coefficient of friction, but also in the prevention of coating failure.
\end{abstract}

Keywords: nickel; tungsten disulphide; hexagonal boron nitride; composite coatings; solid lubricant; tribology

\section{Introduction}

Electrodeposited Ni-based composites coatings [1] have received a wide attention from the research community in recent years due to the enhanced tribological performance that such coatings may exhibit in terms of coefficient of friction $(\mathrm{CoF})$ and wear resistance [2-6]. Nevertheless, most of the studies available in the literature deal with the performance of Ni-based composite coatings with hard particles, whereas the incorporation of inherently soft and lubricant particles such as hBN or $\mathrm{WS}_{2}$ into electrodeposited Ni-based coatings has been studied to a much lesser extent $[7,8]$, despite of the enhancement of both $\mathrm{CoF}$ and wear resistance that could be expected when lubricant particles [9] are incorporated into $\mathrm{Ni}$ coatings.

In a previous work, the authors developed novel $\mathrm{Ni} / \mathrm{WS}_{2}$ and $\mathrm{Ni} / \mathrm{hBN}$ composite coatings (Figs. 1 and 2) electrodeposited from an additive-free Watts bath with the aid of ultrasound [10]. The Ni/WS composite coatings contained $1 \%$ by weight of $\mathrm{WS}_{2}$ particles and, compared to standard pure $\mathrm{Ni}$ electrodeposited from the same bath [11], exhibited an apparently nano-size crystalline structure which resulted in higher hardness. Regarding the Ni/hBN composite coatings, the hBN content was around $0.2 \%$ by weight, and the structure of the coating was similar to that of the benchmark Ni coating (fragmented structured with noticeable columnar crystals), resulting

\footnotetext{
* Corresponding authors: Ignacio TUDELA, E-mail: ignacio.tudela@daidometal.com; YI ZHANG, E-mail: yi.zhang@daidometal.com
} 
in a slightly lower hardness due to the softening effect of the presence of the hBN particles. The tribological performance of these recently developed composite coatings has been initially evaluated in this study to shed more light on the properties of these electrodeposited Ni-based composite coatings containing lubricant particles
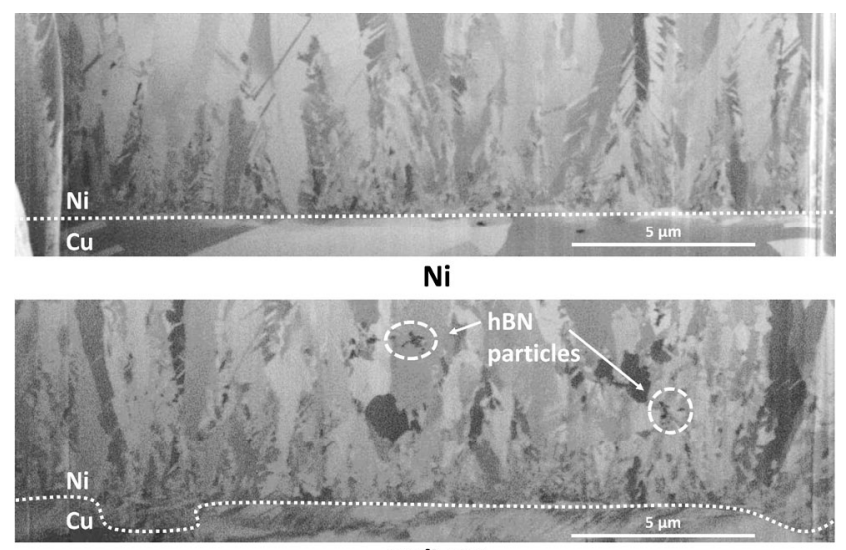

$\mathrm{Ni} / \mathrm{hBN}$

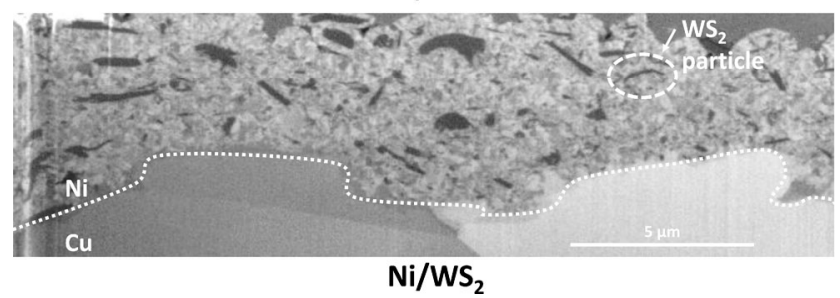

Fig. 1 FIB-SEM images of the cross-section of novel Ni/hBN and $\mathrm{Ni} / \mathrm{WS}_{2}$ composite coatings and standard $\mathrm{Ni}$ coatings used as benchmark. Adapted from Ref. [10], with permission from Elsevier.

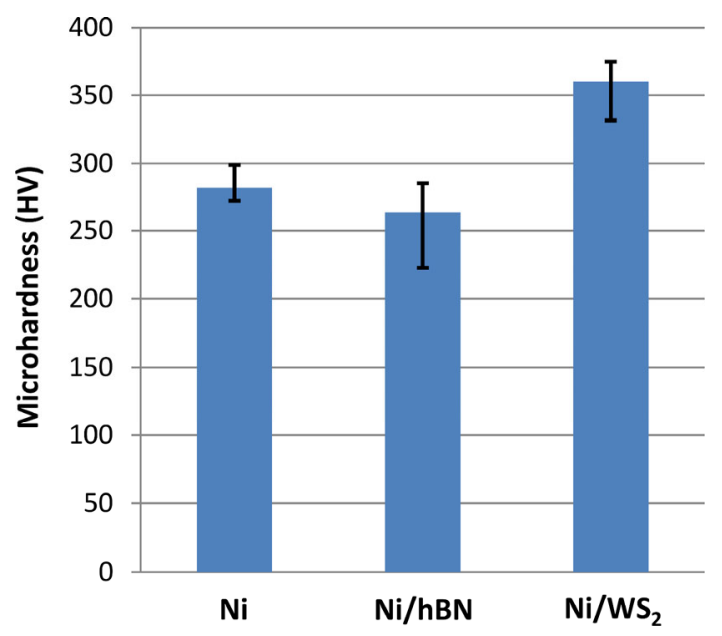

Fig. 2 Microhardness values measured in the central area of novel $\mathrm{Ni} / \mathrm{hBN}$ and $\mathrm{Ni} / \mathrm{WS}_{2}$ composite coatings and standard Ni coatings used as benchmark. Adapted from Ref. [10], with permission from Elsevier.

\section{Materials and methods}

The tribological analysis was performed on the Ni/hBN and $\mathrm{Ni} / \mathrm{WS}_{2}$ composite coatings and the standard pure Ni deposit in order to have an initial idea of the tribological performance of the novel composite coatings. A UMT Scratch Tester (Bruker) was used for this analysis for which a multiple scratch method was developed. Although this method might appear controversial to the reader, scratch tests are a reliable tool for friction measurements at low sliding speeds [12], and multiple scratch tests have been an effective method to evaluate the tribological performance of electrodeposited coatings by capturing the lubricious effects of novel features in the structure of triblogical coatings and eliminating the effect of the surface roughness of the coatings [13].

Scratch tests were performed under two different conditions:

(1) Lubricated scratch tests where lubrication was achieved via a single drop of SAE 10 oil immediately before the tests started in order to study the performance of the electrodeposited Ni-based coatings under "mixed-film"|"boundary" lubrication where the sliding contacting bodies are supported on a combination of asperity-asperity contact points and fluid regions between asperities [14].

(2) Non-lubricated scratch tests where no lubricant was used in order to study the performance of the electrodeposited Ni-based coatings under dry "boundary" lubrication where asperity-asperity contact points fully support the load [15].

The parameters of the scratch tests were:

- Sliding distance: $10 \mathrm{~mm}$;

- Sliding speed: $10 \mathrm{~mm} / \mathrm{min}$;

- Load: $60 \mathrm{~N}$;

- Ball diameter: $6.3 \mathrm{~mm}$;

- Ball material: JIS SUJ2 - ISO 100Cr6;

- Temperature: $20^{\circ} \mathrm{C}$;

- Number of scratches: 10 (starting and ending on the same respective start/end points).

The maximum contact pressure at the start of the tests, assuming a Hertz contact resulting in a circular contact area [16], was estimated around 2.3 GPa for the applied load $(60 \mathrm{~N})$. High-resolution images of the ball and the trace left on the coatings after the tests were obtained with a Keyence optical microscope. 
Detailed 3D images of the middle point of the traces left on the coatings after the tests were also obtained with a white light interferometer (MicroXAM2 from KLA Tencor) to estimate the depth of the resulting wear track.

\section{Results}

\subsection{Lubricated tests}

Figure 3 displays CoF curves obtained during the lubricated scratch tests performed on the novel Ni/hBN and $\mathrm{Ni} / \mathrm{WS}_{2}$ composite coatings and the standard $\mathrm{Ni}$ coating used as a benchmark. For both standard pure $\mathrm{Ni}$ and Ni/hBN coatings (Figs. 3(a) and 3(b), respectively), the lowest $\mathrm{CoF}$ values were measured during the first scratch, progressively increasing with each new scratch until a relatively steady $\mathrm{CoF}$ around 0.3 was achieved. From scratches 2-3, the signal measured apparently showed a significant amount of "noise". A closer look at the CoF curves revealed a very distinctive repetition of cycles alternating a "concave down" increase followed by a sudden drop of CoF. Such repeated feature observed in the CoF curves corresponding to scratches 2 to 10 constitutes a very strong indication of "stick-slip" motion [17]. In stick-slip motion, the test ball virtually stops sliding (maximum observed in each cycle) and then experiences rapid sliding which progressively slows down until it reaches the point where very slow, almost imperceptible sliding motion occurs again [14]. For the $\mathrm{Ni} / \mathrm{WS}_{2}$ composite coatings, the lowest $\mathrm{CoF}$ values were again observed during scratch 1 . In this case though, CoF values slowly increased with each new scratch until a steady $\mathrm{CoF}$ value around 0.24 was achieved in scratch 6, being up to $20 \%$ lower than the CoF values measured for the other Ni-based coatings. In addition, CoF curves did not indicate the occurrence of stick-slick motion in this case, as opposed to what was observed for the other Ni-based coatings tested. In all cases, no signs of critical coating failure were seen in the recorded acoustic emission (AE) signal (AE signal
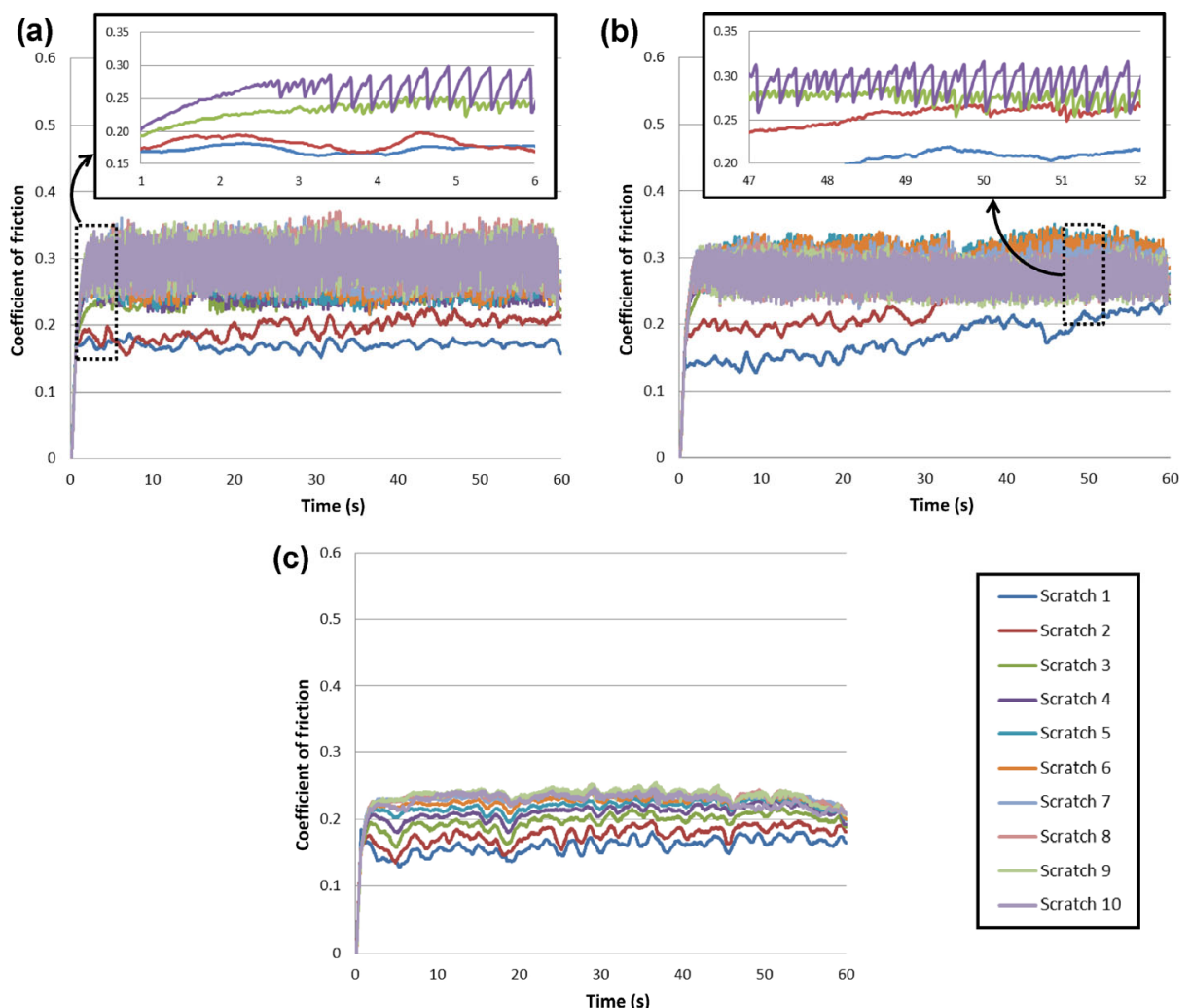

Fig. 3 CoF measured during the lubricated scratch test (10 continuous scratches) performed on: (a) standard pure Ni coating (benchmark material), (b) Ni/hBN composite coating, and (c) Ni/ $\mathrm{WS}_{2}$ composite coating. Zoomed-in graphs in (a) and (b) show when stick-slip motion started to occur (only first scratches are shown for better visibility). 
registered during the scratch tests is available online as Electronic Supplementary Material (ESM)).

Figure 4 displays the surface of the test balls used in the scratch test performed on the different coatings after completion of the scratch test, while Fig. 5 displays the wear track left on the tested samples. In all cases, a small "wear lump" formed as a result of material transfer from the coating to the ball during the scratch test, and accumulation of debris forming ridges on both sides of the wear track was observed. Nevertheless, a few differences were observed in the test ball and the wear track corresponding to the tests performed
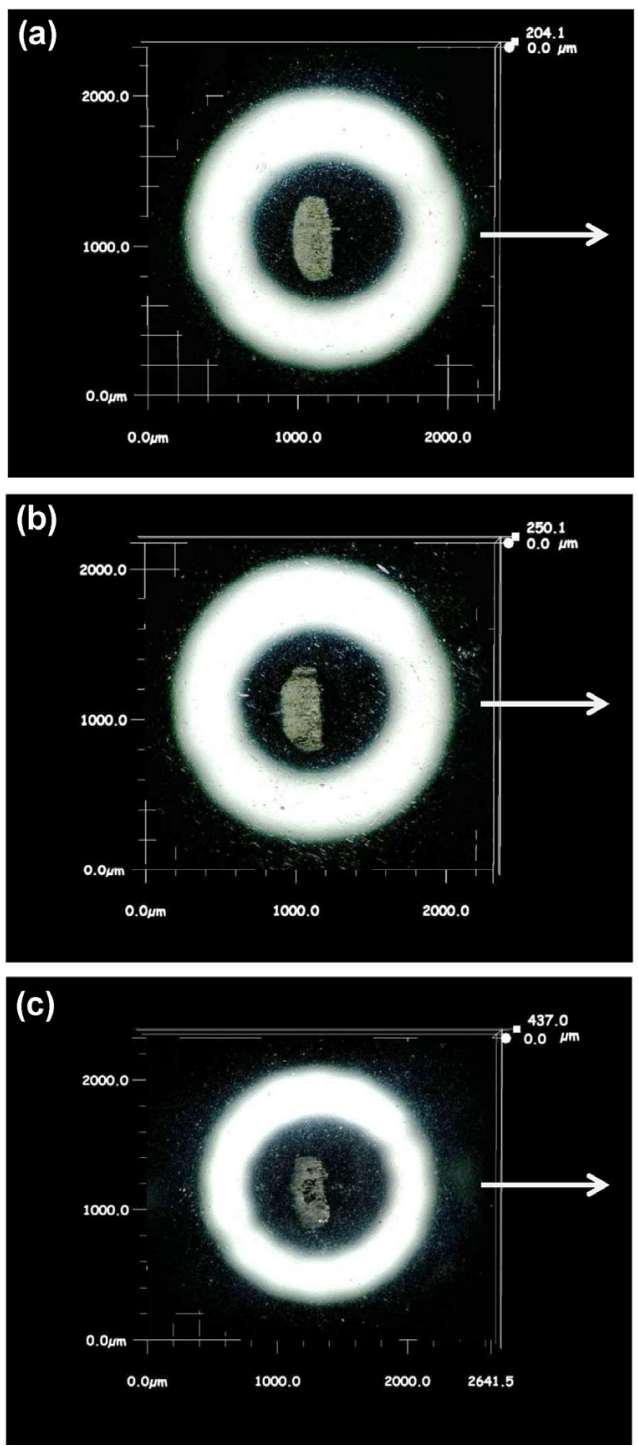

Fig. 4 Images of the test ball after the lubricated scratch tests: (a) standard pure Ni coating (benchmark material), (b) $\mathrm{Ni} / \mathrm{hBN}$ composite coating, and (c) Ni/WS $\mathrm{WS}_{2}$ composite coating. The white arrows point the direction of the sample motion. (a)
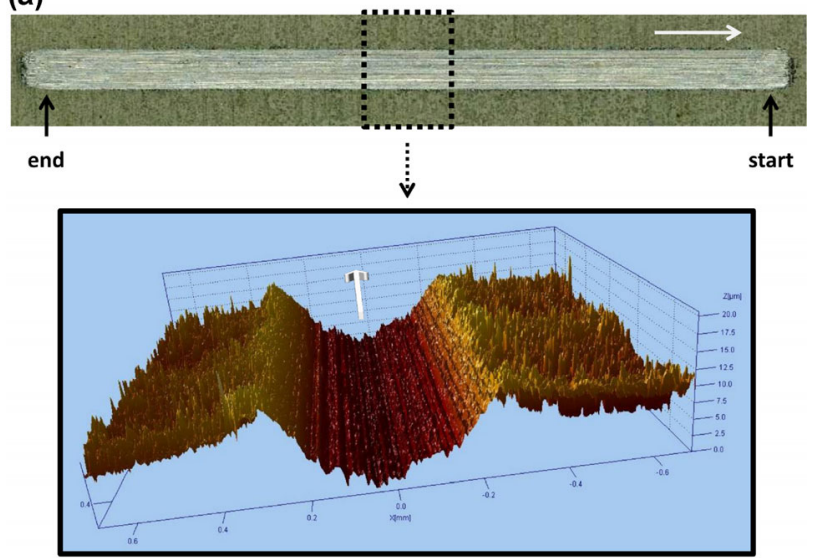

(b)

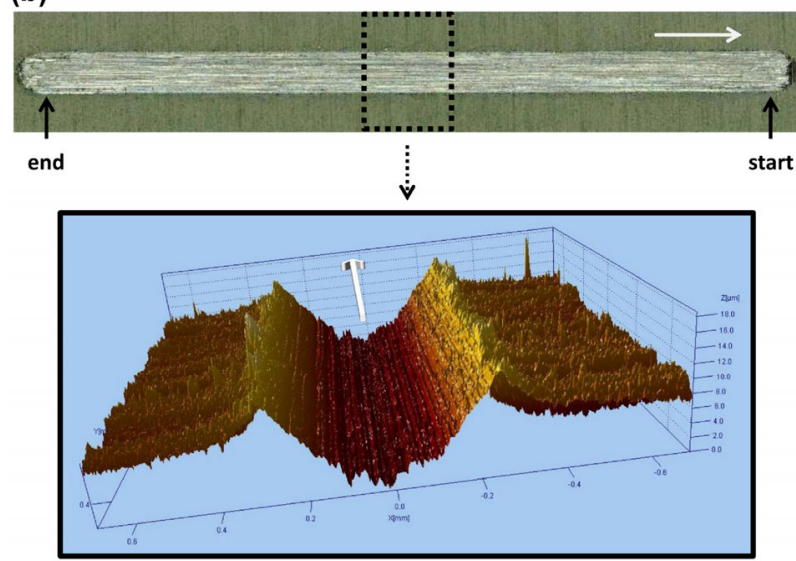

(c)
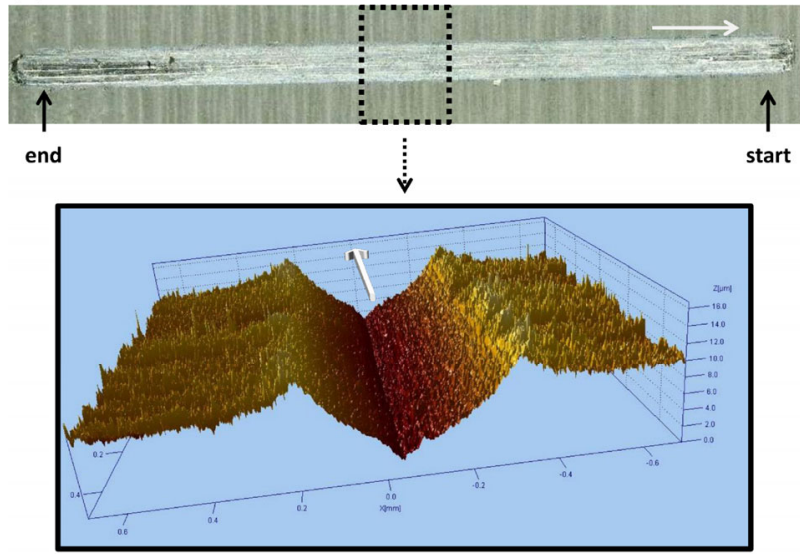

Fig. 5 Images of the test wear track (optical microscope image and $3 \mathrm{D}$ depth profile on the middle area of the track) left on the surface after the lubricated scratch tests: (a) standard pure $\mathrm{Ni}$ coating (benchmark material), (b) $\mathrm{Ni} / \mathrm{hBN}$ composite coating, and (c) $\mathrm{Ni} / \mathrm{WS}_{2}$ composite coating. The white arrows point the direction of the sample motion.

on the Ni/WS ${ }_{2}$ composite coating (Figs. 4(c) and 5(c), respectively) compared with those corresponding to the Ni/hBN composite coatings (Figs. 4(b) and 5(b), 
respectively) and the standard $\mathrm{Ni}$ deposit used as a benchmark (Figs. 4(a) and 5(a), respectively). For the $\mathrm{Ni} / \mathrm{WS}_{2}$ composite coating, the contact area of the wear lump attached to the test ball presented a smooth black surface suggesting the formation of a thin tribofilm during the tests. Also, a smaller amount of worn-out material accumulated on the sides of the wear track of the $\mathrm{Ni} / \mathrm{WS}_{2}$ composite, which exhibited a smoother appearance with low wear at the end of the wear track. The latter can be easily seen in Fig. 6, which displays the cross-sectional depth profile measured at the middle of each wear track in order to compare the depth of each wear track and the debris accumulated on the sides of the track. It is also worth pointing out that, taking into account the thickness of the coatings ( $6 \mu \mathrm{m}$ in all cases), the final scratches would partially take place over the $\mathrm{Pb}$-bronze substrate, especially in both Ni deposits and the Ni/hBN composite coating, where only a small portion of the test ball would be in contact with the Pb-bronze substrate in the $\mathrm{Ni} / \mathrm{WS}_{2}$ composite coating.

\subsection{Non-lubricated tests}

Figure 7 displays CoF curves obtained during the non-lubricated scratch tests performed on the novel $\mathrm{Ni} / \mathrm{hBN}$ and $\mathrm{Ni} / \mathrm{WS}_{2}$ composite coatings and the benchmark Ni coating. For the Ni coating (Fig. 7(a)), although reasonably low CoF values were measured during scratch 1 , very high $\mathrm{CoF}$ values up to 0.6 were observed in scratch 2 , which showed a very chaotic

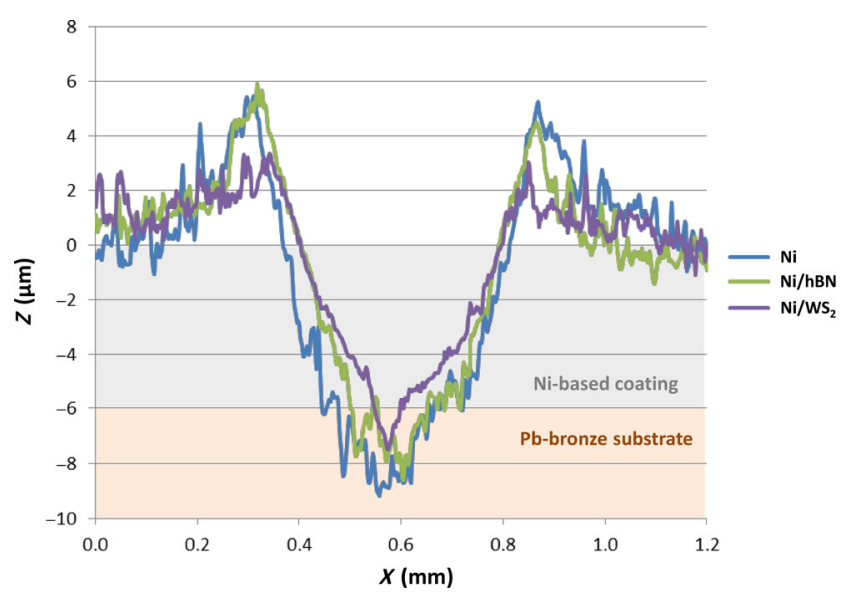

Fig. 6 Cross-sectional depth profile measured at the middle of the wear track left by the test ball during the lubricated scratch tests (10 continuous scratches) performed on different Ni-based coatings. trend with no clear average CoF value. Scratches 3 and 4 yielded $\mathrm{CoF}$ curves showing an intermediate behaviour between scratches 1 and 2, and the system seemed to settle down from scratch 5 onwards. The AE signal was also recorded during the non-lubricated scratch test (available online as ESM) showing in this case very clear signal peaks indicating critical failure of the coatings on different scratches. Regarding this, a very strong signal peak was recorded during scratch 3. It was, at this latter point, where significant coating failure occurred, reflected in the fact that the system seemed to start settling down from that point onwards. Once the system had settled down, $\mathrm{CoF}$ values remained between 0.2 and 0.3 . For the $\mathrm{Ni} / \mathrm{hBN}$ composite coating (Fig. 7(b)), low CoF values depicting a smooth curve were again measured during scratch 1 . CoF values measured from scratch 2 onwards did not fluctuate as much as in the case of the benchmark $\mathrm{Ni}$ coatings, and CoF values decreased during the second half of the scratches, possibly due to the action of the hBN particles, which could have more influence in this case due to the absence of a liquid lubricant than in the lubricated scratch tests. The $\mathrm{CoF}$ values measured during scratch 5 seemed to follow the same trend of previous scratches until a significant drop in $\mathrm{CoF}$ was observed after 10-15 seconds, when a first AE signal peak was observed (available online as ESM) due to coating failure. After that point, $\mathrm{CoF}$ values went down during the rest of the scratches and the tribosystem settled down and $\mathrm{CoF}$ values around $0.2-0.25$ were measured from scratch 6 onwards. For the Ni/WS composite coating, the $\mathrm{CoF}$ curves obtained during the different scratches were very similar, ranging between 0.15 and 0.3 during the whole experiment. As opposed to what was observed for the other Ni-based coatings evaluated under non-lubricated conditions, no signs of coating failure were seen in the recorded $\mathrm{AE}$ signal (available online as ESM).

Figure 8 displays the surface of the test balls after the non-lubricated scratch test performed on the different coatings here evaluated, while Fig. 9 displays the surface of wear track left on the tested samples. For the benchmark Ni coatings and the novel Ni/hBN composite coatings (Figs. 8(a) and 8(b), respectively), material transfer from the coating to the ball was far more significant now under non-lubricated conditions, showing very distinctive ridges and asperities on the 

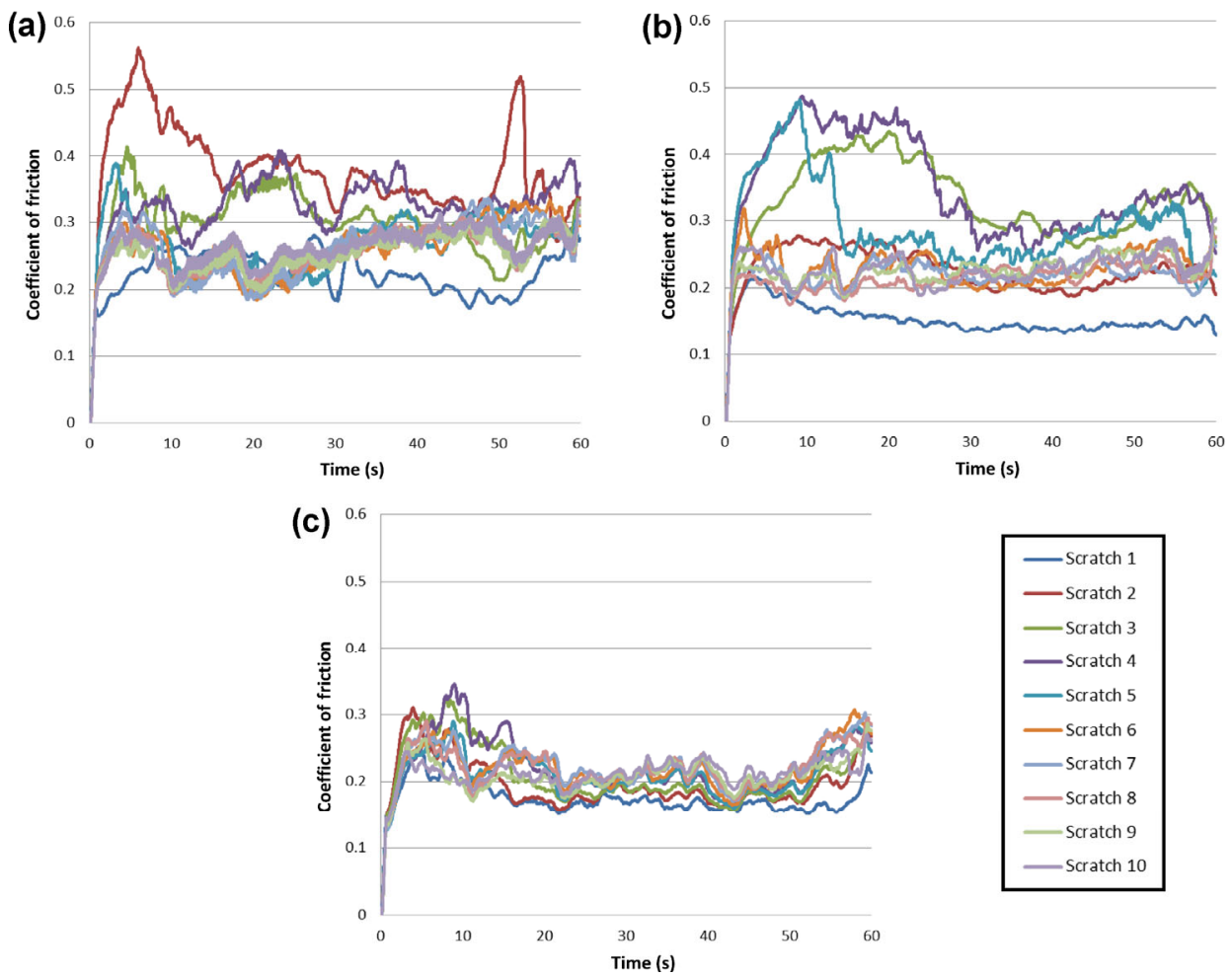

Fig. 7 CoF measured during the non-lubricated scratch test (10 continuous scratches) performed on: (a) standard pure Ni coating (benchmark material), (b) $\mathrm{Ni} / \mathrm{hBN}$ composite coating, and (c) $\mathrm{Ni} / \mathrm{WS}_{2}$ composite coating.
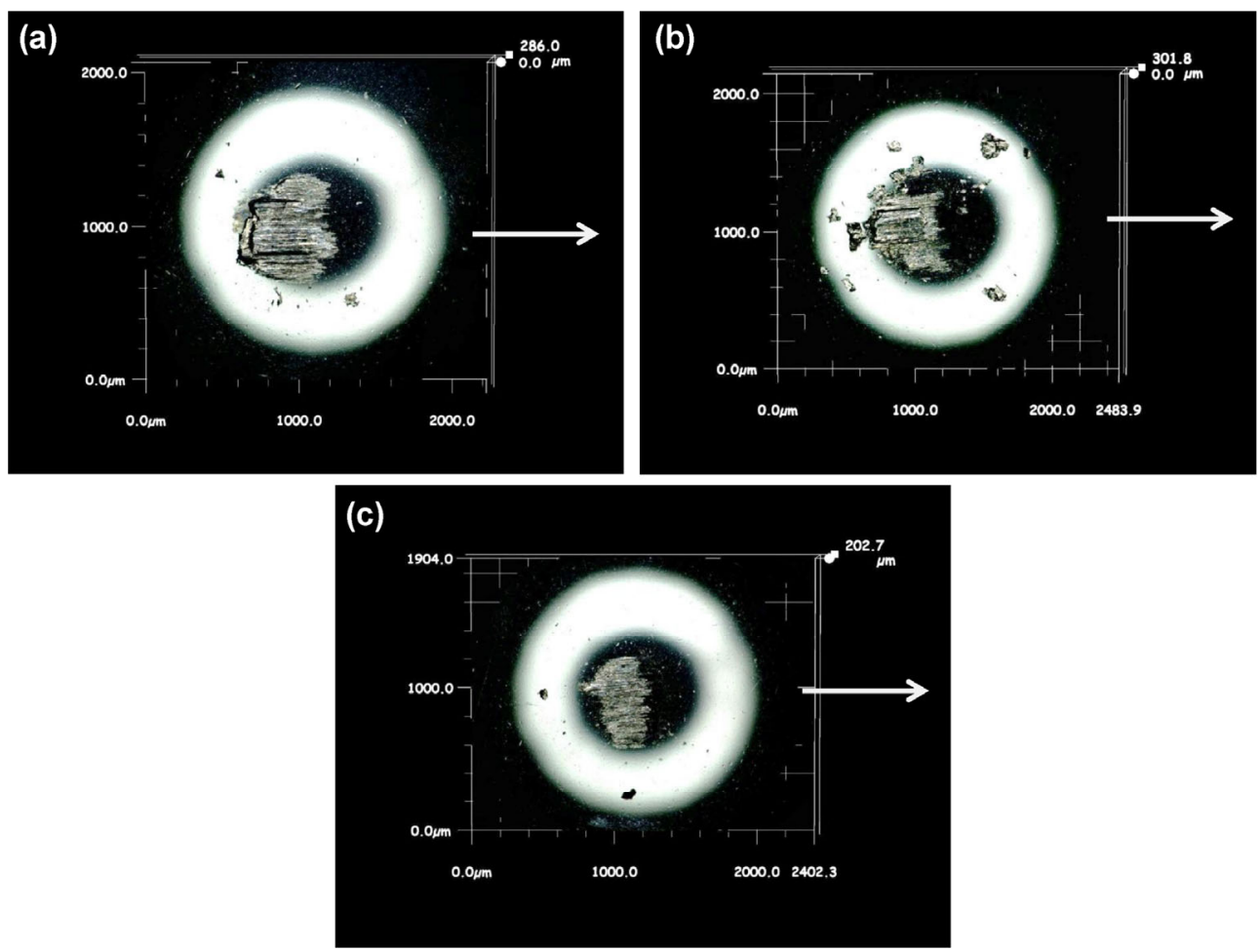

Fig. 8 Images of the test ball after the non-lubricated scratch tests: (a) standard pure Ni coating (benchmark material), (b) Ni/hBN composite coating, and (c) Ni/WS $\mathrm{WS}_{2}$ composite coating. The white arrows point the direction of the sample motion. 


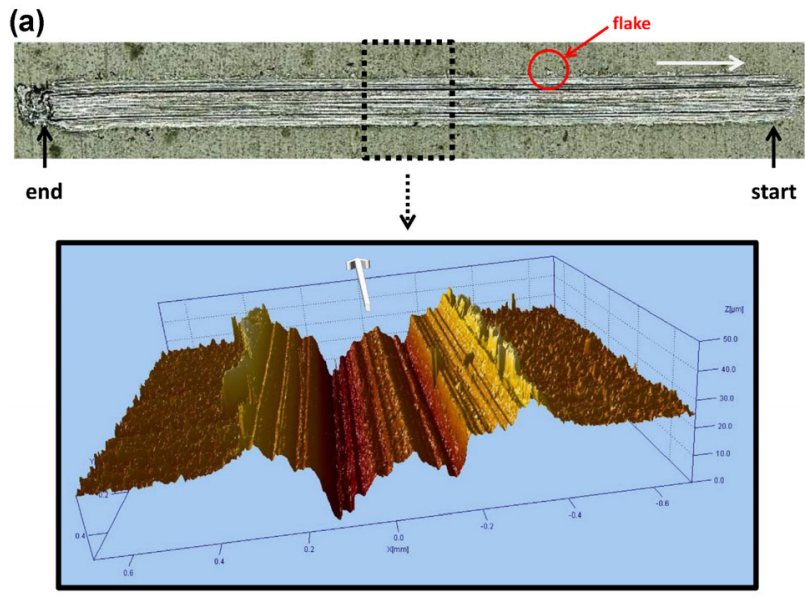

(b) flake

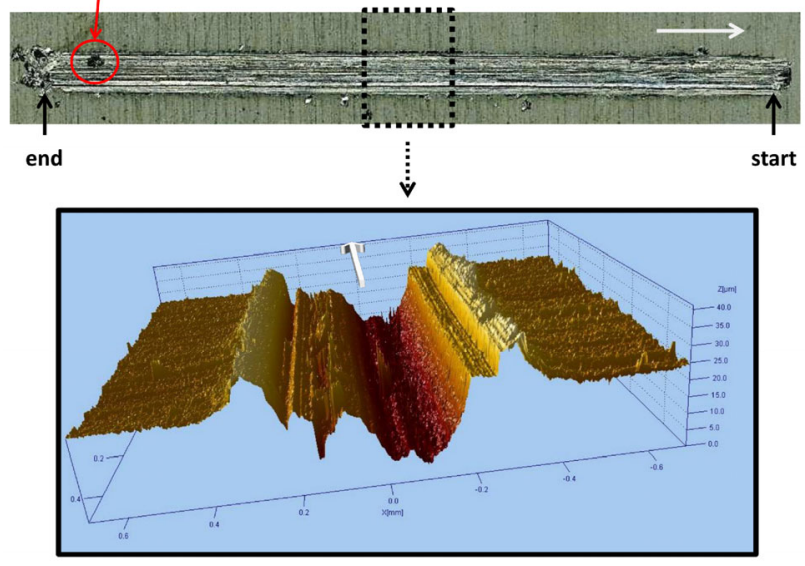

(c)
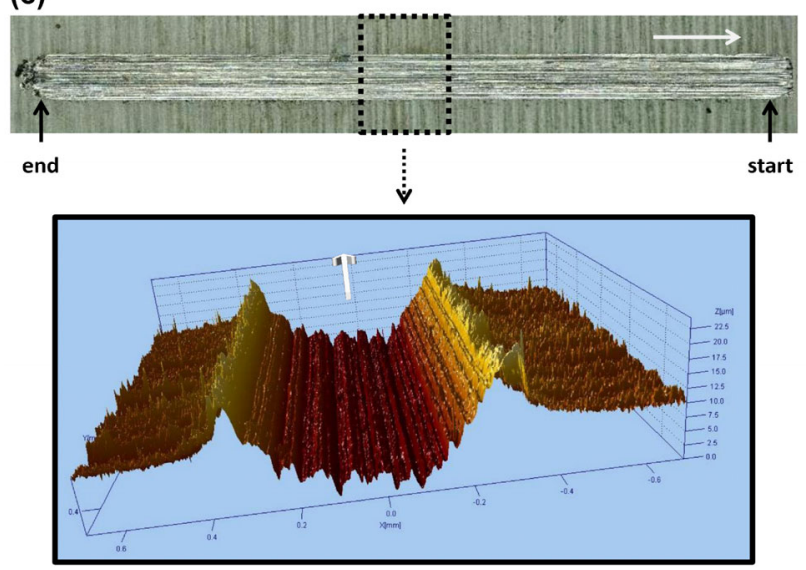

Fig. 9 Images of the test wear track (optical microscope image and 3D depth profile on the middle area of the track) left on the surface after the non-lubricated scratch tests: (a) standard pure $\mathrm{Ni}$ coating (benchmark material), (b) Ni/hBN composite coating, and (c) $\mathrm{Ni} / \mathrm{WS}_{2}$ composite coating. The white arrows point the direction of the sample motion.

surface of the wear lump attached to the test ball. These distinctive asperities matched the deep scratches observed on the surface of the wear tracks left on these samples coated with said coatings (Figs. 9(a) and 9(b), respectively). The wear tracks were now much rougher and irregular and presented a greater amount of debris on the sides of the tracks forming greater ridges than the wear tracks left in samples coated with the same coatings after the lubricated scratch test. In addition, a significant number of flat flakes were clearly noticed around the ridges and over the wear tracks and the test balls for both coatings. For the $\mathrm{Ni} / \mathrm{WS}_{2}$ composite coating, a reasonably large wear lump was observed in the test ball used during the non-lubricated scratch test (Fig. 8(c)), although in this case the amount of material transferred from the ball to the coating was not as significant as in the non-lubricated scratch tests performed on samples coated with the other Ni-based coatings here presented. A smaller amount of worn-out material forming ridges on both sides of the wear track was observed in the sample coated with the $\mathrm{Ni} / \mathrm{WS}_{2}$ composite coating (Fig. 9(c)). Little accumulation was also noticed at the end of the wear track, as opposed to the larger amount of debris that was observed on the other Ni-based coatings tested under the same non-lubricated conditions. Although the surface of the wear track left after the non-lubricated scratch test was not as smooth as the one left after the lubricated test (some scratches were clearly seen in this case), it was far more rounded than the wear track left in the samples coated with the other Ni-based coatings. In addition, just a few flakes were noticed around the wear track and in the test ball.

Significant differences were also observed when comparing the cross-sectional depth profile measured at the middle of each wear track left after non-lubricated scratch tests performed on the Ni-based coatings tested (Fig. 10). Whereas very irregular wear tracks with very deep scratches (up to $25 \mu \mathrm{m}$ depth) were produced in the benchmark Ni and the Ni/hBN composite coatings, a reasonably smoother wear track with far less deeper and irregular scratches (up to $11 \mu \mathrm{m}$ deep) was always left on the samples coated with the $\mathrm{Ni} / \mathrm{WS}_{2}$ composite coating. The cause for the depth achieved in the benchmark $\mathrm{Ni}$ and $\mathrm{Ni} / \mathrm{hBN}$ composite coatings was the abrasive action of the hard $\mathrm{Ni}$ asperities formed on the large wear lumps formed covering the contact surface of the test balls. As a result, the test ball ended up sliding mainly over the $\mathrm{Pb}$-bronze substrate in the samples coated with both the benchmark $\mathrm{Ni}$ and 


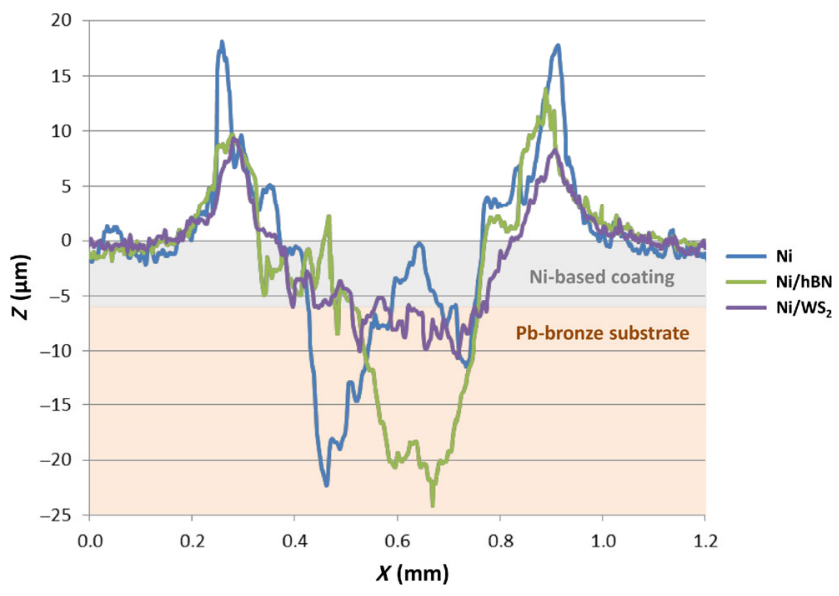

Fig. 10 Cross-sectional depth profile measured at the middle of the wear track left by the test ball after the non-lubricated scratch test (10 continuous scratches) performed on different Ni-based coatings.

$\mathrm{Ni} / \mathrm{hBN}$ composite coatings, and hence the decrease in CoF values down to $0.2-0.3$ once the coating had failed and the tribosystem had settled down. In the case of the $\mathrm{Ni} / \mathrm{WS}_{2}$ composite coatings though, the ball was still partially sliding over the coating after 10 scratches with relatively constant $\mathrm{CoF}$ or around 0.22 .

\section{Discussion}

Under lubricated conditions (Fig. 11), the standard pure $\mathrm{Ni}$ deposits used as the benchmark coating material and the Ni/hBN composite coatings exhibited very similar behaviour, not only in terms of the $\mathrm{CoF}$ values measured, but also in terms of the stick-slip motion developed during the course of the tests. In all the tests performed on these coatings, stick-slip motion routinely started during the second half of scratch 2 or early on during scratch 3 . Stick-slip motion would occur as a result of the combination of $\mathrm{Ni}-\mathrm{Ni}$ sliding contact in the presence of the lubricant. $\mathrm{Ni}-\mathrm{Ni}$ sliding contact took place due to the formation and growth of the wear lump on the ball by the repeated sliding action of the ball on the tested sample (lower $\mathrm{CoF}$ values and no signs of stick-slip motion were observed during the first scratch for the $\mathrm{Ni} / \mathrm{hBN}$ composite coating and the Ni deposits as no material had been transferred from the coating to the ball yet). High friction is expected in those situations where $\mathrm{Ni}-\mathrm{Ni}$ sliding contact occurs, whereas low friction is expected when a lubricant film forms between the

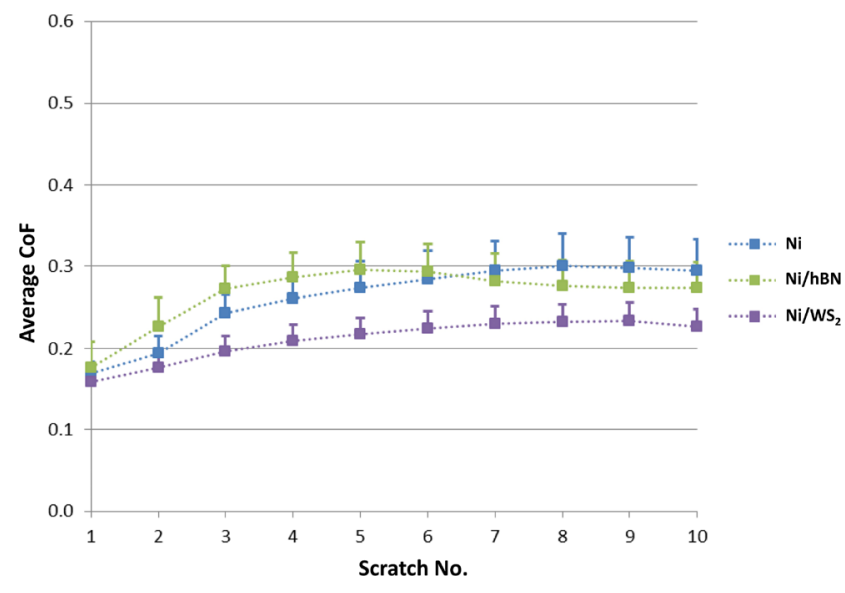

Fig. 11 Average and maximum CoF obtained from lubricated scratch tests (10 continuous scratches) performed on standard pure $\mathrm{Ni}$ coating (benchmark material), Ni/hBN composite coating, and $\mathrm{Ni} / \mathrm{WS}_{2}$ composite coating. Bars depict the maximum $\mathrm{CoF}$ value measured during each scratch.

sliding surface and the counter-part, and hence the stick-slip phenomenon observed for these coatings. This would be partly due to the generally poor tribological performance of $\mathrm{Ni}$, especially once there has been a transfer of material from the coating to the test ball, but also due to the harsh mixed-film/ boundary lubrication regime expected in a tribosystem such as the one studied (test ball/lubricant/Ni-based coating/high hertzian-contact pressure/slow sliding) where the load is borne partly by the lubricant film and partly by the asperities present in the surface of the test ball and the wear track formed in the coating [18]. The features observed in the test ball (formation of a wear lump on its surface) and the surface of the tested samples (fairly regular wear track with ridges formed on both sides) would suggest that ploughinglike abrasive wear occurred during the test, where repeated sliding and accumulation of plastic flow at the surface of the coating would result in the formation and growth of the wear lump observed in the test ball [19].

The novel Ni/WS ${ }_{2}$ composite coatings exhibited a very different behaviour under lubricated conditions (Fig. 11), not only in terms of CoF (up to 20\% lower), but also in terms of sliding motion, as smooth sliding occurred with no signs of the stick-slip phenomenon previously reported for the other Ni-based coatings tested. As a consequence of the smooth sliding, the wear track left in the $\mathrm{Ni} / \mathrm{WS}_{2}$ composites coatings after the scratch tests was not only shallower than the wear 
tracks left in the other Ni-based coatings evaluated, but also presented a smoother surface with a smaller amount of debris accumulated on the sides of the track. Again, ploughing-like abrasive wear would be the wear mechanism in this case. The causes for this beneficial presence of the $\mathrm{WS}_{2}$ particles in lubricated tribosystems are diverse: (i) rolling friction [20], (ii) $\mathrm{WS}_{2}$ particles acting as spacers, preventing the contact between the asperities in both metal surfaces [20], (iii) third body material transfer (i.e., gradual transference of layers of $\mathrm{WS}_{2}$ onto the metal surfaces during repeated sliding) [21], and (iv) the gradual formation of a thin $\mathrm{WS}_{2}$ film after continuous and repeated sliding [22]. In the latter referenced study, a thin black $W_{2}$ film gradually formed on the metal surface, very similar to the black film observed on the contact surface of the test ball used for the scratch test performed on the Ni/WS $\mathrm{WS}_{2}$ composite coating (Fig. 5(c)). The potential formation of a thin $\mathrm{WS}_{2}$ film would protect the contact surface and restrict the rise of the friction force, decreasing the influence of asperity contact and improving the tribological performance of the whole system under mixed-filmed lubrication [23].

Under non-lubricated conditions, high $\mathrm{CoF}$ values were observed for the benchmark $\mathrm{Ni}$ and the Ni/hBN composite coatings after scratch 1 (Fig. 12). These materials would eventually fail after a few scratches: the Ni coatings routinely failed during scratch 3, while the Ni/hBN composite coatings generally failed during scratches 4 or 5 . In both cases, coating failure was preceded by the highest average CoF value, which would be measured in the scratch prior to the one where coating failure was actually noticed. Different phenomena would contribute to the occurrence of coating failure such as changes in the area of contact and surface temperature [17], which would be expected where very similar/compatible materials are in contact with an absence of lubrication as in non-lubricated $\mathrm{Ni}-\mathrm{Ni}$ contact resulting from the formation of a wear lump in the test ball after continuous sliding. Regarding the wear mechanism, the matching between the asperities formed on the wear lumps and the surface of the wear tracks suggest that these hard abrasive asperities were formed by work hardening, phase transitions and third-body formation at the contact interface during repeated and continuous sliding [19], indicating the occurrence of

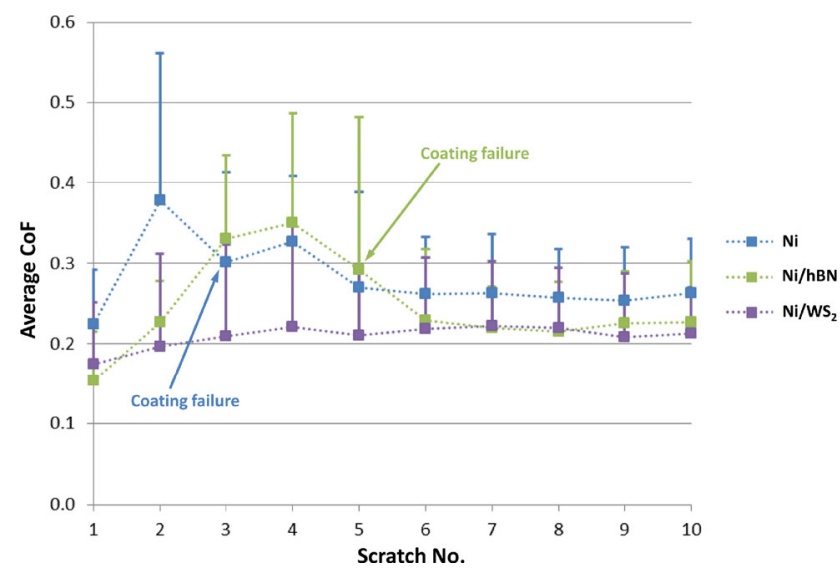

Fig. 12 Average and maximum CoF obtained from non-lubricated scratch tests (10 continuous scratches) performed on standard pure $\mathrm{Ni}$ coating (benchmark material), $\mathrm{Ni} / \mathrm{hBN}$ composite coating and $\mathrm{Ni} / \mathrm{WS}_{2}$ composite coating. Bars depict the maximum $\mathrm{CoF}$ value measured during each scratch.

ploughing-like abrasive wear during the non-lubricated scratch test. A different matter is the presence of flat flakes around the ridges and over the wear tracks and test balls. These flakes would originate from deformed surface material caused by heavy sliding contact [24]:

(1) As Ni-Ni contact occurs under non-lubricated conditions, strong "adhesive effect" between the "softer" areas of the surface of the wear lump in the test ball and the surface of the wear track might be expected due to high material compatibility.

(2) Tangential shear under compression when strong "adhesive effect" occurs generates "slips" along slip planes in the contact region, resulting in the formation of flake-like shear tongues [19].

Some of these flakes would adhere to the surface of the wear lump during continuous sliding, and hence the larger wear lumps observed in the scratch tests performed in the absence of lubrication. In addition, large amounts of accumulated, plastically-deformed debris were left at the end of the wear tracks generated on the samples coated with both benchmark Ni coatings and the novel Ni/hBN composite coatings, growing after each scratch due to partial removal of the debris attached to the wear lump in the ball and the accumulation of flakes in that area. These latter features are characteristic of adhesive wear [19], which would gain much more importance in the "dry" scratch tests due to the absence of a liquid lubricant. Overall, combined abrasive-adhesive wear would be the wear mechanism during the non-lubricated scratch tests, 
as opposed to the more abrasive wear observed in the lubricated tests. Combined abrasive-adhesive wear with lack of lubrication would therefore be responsible for the cohesive coating failure and the severe wear observed, as no evidence of delamination due to adhesive failure was observed between the coating and the substrate.

The Ni/WS $\mathrm{WS}_{2}$ composite coatings again exhibited a very different behaviour under non-lubricated conditions, not only due to the reasonably smooth and constant $\mathrm{CoF}$ values measured during the consecutive scratches (Fig. 12), but also due to the fact that the $\mathrm{Ni} / \mathrm{WS}_{2}$ composite coatings did not fail during any of the non-lubricated scratch tests performed on these coatings. The main reason for this would again be the presence of the $\mathrm{WS}_{2}$ particles. Nevertheless, no thin $\mathrm{WS}_{2}$ film apparently formed on either the wear track or the test ball used. In addition, asperities still formed on the surface of the wear lump in the test ball, resulting in the appearance of scratches in the wear track. This leads to the assumption that, in this case, $\mathrm{WS}_{2}$ particles would act as a solid lubricant lowering $\mathrm{CoF}$ by rolling friction mechanisms as suggested by Rapoport et al. [20]. Rolling friction mechanisms provided by $\mathrm{WS}_{2}$ nanoparticles were also suggested by García-Lecina et al. [8] after their non-lubricated tribological experiments (ball-on-disc tests conducted under very low loads of $1 \mathrm{~N}$ ) performed on ultrasoundassisted electrodeposited $\mathrm{Ni}$ composite coatings with inorganic-like fullerene $\mathrm{WS}_{2}\left(\mathrm{IF}-\mathrm{WS}_{2}\right)$ particles, where some of the IF-WS $S_{2}$ particles incorporated into the coating would be released, serving as spacers and preventing asperity contact between the mating surfaces. A different friction mechanism, also under non-lubricated conditions, was suggested by Sivandipoor and Ashrafizadeh for their electroless deposited $\mathrm{Ni}-\mathrm{P} / \mathrm{WS}_{2}$ composite coatings (pin-on-disc tests also conducted under very low loads of $1 \mathrm{~N}$ ), as they reported the formation of a $\mathrm{WS}_{2}$-rich film forming discrete regions along the surface of the wear track left on the tested coatings [25]. No clear evidence of such films was noticed in the non-lubricated tests performed on the $\mathrm{Ni} / \mathrm{WS}_{2}$ composite coatings developed during the present research project. Nevertheless, the potential presence and contribution of these $\mathrm{WS}_{2}$-rich regions on the surface of the wear track must not be discarded, and more detailed studies are on their way in order to fully understand the friction mechanisms that may take place when $\mathrm{WS}_{2}$ particles are incorporated into $\mathrm{Ni}$ coatings used as tribologically active layers in non-lubricated tribological systems. The latter is of particular importance, as all of the more fundamental research dealing with the friction mechanisms in systems with the presence of $\mathrm{WS}_{2}$ particles is mainly focused on the use of $\mathrm{WS}_{2}$ particles in lubricated systems [20-26].

Overall, the incorporation of $\mathrm{WS}_{2}$ particles into electrodeposited $\mathrm{Ni}$ coatings remarkably enhances their tribological performance either under lubricated or non-lubricated conditions. Regarding the lower CoF and absence of stick-slip motion observed during lubricated tests, such improvement would be a consequence of the lubricious nature of the $\mathrm{WS}_{2}$ particles. Regarding the apparently higher wear resistance of the $\mathrm{Ni} / \mathrm{WS}_{2}$ composites, roughly indicated by the shallower wear tracks measured for these coatings under both lubricated and non-lubricated conditions, it is worth discussing the work of Sivandipoor and Ashrafizadeh [25]. Their work is interesting because it deals with an electroless Ni-P coating with amorphous structure as deposited, implying that no grain refinement could ever influence the tribological performance of such coatings. In their case, the incorporation of $\mathrm{WS}_{2}$ particles into said coatings resulted in a significant reduction of hardness due to the soft nature of $\mathrm{WS}_{2}$ in comparison with $\mathrm{Ni}$. Although their Ni-P/WS $\mathrm{WS}_{2}$ composite coatings presented a lower CoF than their bechmark Ni-P coatings due to the presence of $\mathrm{WS}_{2}$ particles within the coating, they also exhibited higher weight loss during wear tests due to the lower hardness. Grain size refinement in crystalline Ni deposits, which is often achieved by adding grain-refining additives (e.g., saccharine) into $\mathrm{Ni}$ plating baths, has a remarkable effect on the hardness and wear resistance of electrodeposited $\mathrm{Ni}$ coatings $[27,28]$, but generally little effect on the CoF [27. Therefore, whereas lower $\mathrm{CoF}$ and absence of stick-slip motion during lubricated tests in the Ni/ $\mathrm{WS}_{2}$ composite coatings here presented can directly be attributed to the presence of the $\mathrm{WS}_{2}$ particles within the Ni matrix, the apparent higher wear resistance can be related to the significantly smaller grain size and consequent higher hardness of the composite coating. It must be pointed out that this remarkable grain refinement and consequent increase in hardness were achieved by incorporating the $\mathrm{WS}_{2}$ particles into the coating [10].

Regarding the novel Ni/hBN composites, their 
lack of enhancement in tribological performance both under lubricated and non-lubricated conditions would be related to different causes:

- Particle content. Whereas a noticeable amount of particles could be clearly seen within the Ni matrix in the $\mathrm{Ni} / \mathrm{WS}_{2}$ composite coatings $(1.0 \%$ by weight according to GD-OES analysis), a significantly smaller amount of hBN particles were observed in the $\mathrm{Ni} / \mathrm{hBN}$ composite coatings (around $0.2 \%$ by weight according to GD-OES analysis) [10].

- Low tribological performance of $h B N$ particles in electrodeposited Ni-based composites. Although hBN powder is routinely reported as an effective solid lubricant, previous works with electrodeposited $\mathrm{Ni} / \mathrm{hBN}$ composite coatings showed no change in terms of CoF compared with pure Ni deposits [7], agreeing to some extent with the results obtained under lubricated and non-lubricated conditions in the present study.

\section{Conclusions}

Whereas novel $\mathrm{Ni} / \mathrm{hBN}$ composite coatings show a tribological performance similar to that of a pure $\mathrm{Ni}$ deposit, novel Ni/WS ${ }_{2}$ composite coatings exhibited a remarkable enhancement of the tribological performance under both lubricated and non-lubricated conditions. Under lubricated conditions, a thin tribofilm grew on the surface of the wear lump formed on the test ball resulting in lower coefficient of friction and prevention of stick-slip motion. Under non-lubricated conditions, reasonably smooth sliding was achieved due to the potential release and presence of $\mathrm{WS}_{2}$ particles in the contact, resulting in lower coefficient of friction of the coating, and prevention of coating failure.

\section{Acknowledgments}

The authors acknowledge TSB (now Innovate UK) and EPSRC in UK for their funding through the KTP scheme. The authors would also like to thank Dr James Bowen (Open University) for his assistance with white light interferometry analysis performed at the University of Birmingham.

Electronic Supplementary Material: Supplementary material is available in the online version of this article at https://doi.org/10.1007/s40544-018-0211-0.
Open Access: The articles published in this journal are distributed under the terms of the Creative Commons Attribution 4.0 International License (http:// creativecommons.org/licenses/by/4.0/), which permits unrestricted use, distribution, and reproduction in any medium, provided you give appropriate credit to the original author(s) and the source, provide a link to the Creative Commons license, and indicate if changes were made.

\section{References}

[1] Low C T J, Wills R G A, Walsh F C. Electrodeposition of composite coatings containing nanoparticles in a metal deposit. Surf Coat Technol 201:371-383 (2006)

[2] Wang W, Hou F-Y, Wang H, Guo H-T. Fabrication and characterization of $\mathrm{Ni}-\mathrm{ZrO}_{2}$ composite nano-coatings by pulse electrodeposition. Scripta Mater 53: 613-618 (2005)

[3] Lekka M, Kouloumbi N, Gajo M, Bonora P L. Corrosion and wear resistant electrodeposited composite coatings. Electrochim Acta 50: 4551-4556 (2005)

[4] Feng Q, Li T, Yue H, Qi K, Bai F, Jin J. Preparation and characterization of nickel nano- $\mathrm{Al}_{2} \mathrm{O}_{3}$ composite coatings by sediment co-deposition. Appl Surf Sci 254: 2262-2268 (2008)

[5] Tian L, Xu J. Electrodeposition and characterization of $\mathrm{Ni}-\mathrm{Y}_{2} \mathrm{O}_{3}$ composite. Appl Surf Sci 257: 7615-7620 (2011)

[6] García-Lecina E, García-Urrutia I, Díez JA, Morgiel J, Indyka P. A comparative study of the effect of mechanical and ultrasound agitation on the properties of electrodeposited $\mathrm{Ni} / \mathrm{Al}_{2} \mathrm{O}_{3}$ nanocomposite coatings. Surf Coat Technol 206: 2998-3005 (2012)

[7] Pompei E, Magagnin L, Lecis N, Cavallotti P.L. Electrodeposition of nickel-BN composite coatings. Electrochim Acta 54: 2571-2574 (2009).

[8] García-Lecina E, García-Urrutia I, Díez J.A, Fornell J, Pellicer E, Sort J. Codeposition of inorganic fullerene-like $\mathrm{WS}_{2}$ nanoparticles in an electrodeposited nickel matrix under the influence of ultrasoni cagitation. Electrochim Acta 114: 859-867 (2013)

[9] Erdemir A. Solid lubricants and self-lubricating films. In Modern Tribology Handbook. Bhushan B, Ed. Boca RatonLondon-New York-Washington DC: CRC Press, 2000.

[10] Tudela I, Zhang Y, Pal M, Kerr I, Cobley A J. Ultrasoundassisted electrodeposition of thin nickel-based composite coatings with lubricant particles. Surf Coat Technol 276: 89-105 (2015)

[11] Tudela I, Zhang Y, Pal M, Kerr I, Mason T J, Cobley A J. Ultrasound-assisted electrodeposition of Nickel: Effect of ultrasonic power on the characteristics of thin coatings. Surf Coat Technol 264: 49-59 (2015)

[12] Nieminen I, Andersson P, Holmberg K. Friction measurement by using a scratch test method. Wear 130: 167-178 (1989)

[13] Anand M, Burmistroviene G, Tudela I, Verbickas R, Lowman G, Zhang Y. Tribological evaluation of multilayer coatings for wear applications based on a novel multiple 
scratch test method. Wear in press (2017)

[14] Ludema K C. Friction. In Modern Tribology Handbook. Bhushan B, Ed. Boca Raton-London-New York-Washington DC: CRC Press, 2000.

[15] Hsu S M, Gates R S. Boundary lubrication and boundary lubriating films. In Modern Tribology Handbook. Bhushan B, Ed. Boca Raton-London-New York-Washington DC: CRC Press, 2000.

[16] Williams J A, Dwyer-Joyce R S. Contact between solid interfaces. In Modern Tribology Handbook. Bhushan B, Ed. Boca Raton-London-New York-Washington DC: CRC Press, 2000.

[17] Bowden F P, Tabor D. The friction and lubrication of solids. Oxford: Oxford University Press, Oxford, 1954 (reprinted as part of Oxford Classic Series 2001).

[18] Spikes H A. Mixed lubrication-An overview. Lubr Sci 9: 221-253 (1997)

[19] Kato K, Adachi K. Wear Mechanisms. In Modern Tribology Handbook. Bhushan B, Ed. Boca Raton-London-New York-Washington DC: CRC Press, 2000.

[20] Rapoport L, Bilik Y, Feldman Y, Homyonfer M, Cohen S R, Tenne R. Hollow nanoparticles of $\mathrm{WS}_{2}$ as potential solid-state lubricants. Nature 387: 791-793 (1997)

[21] Golan Y, Drummond C, Homyonfer M, Feldman Y, Tenne R, Israelachvily J. Microtribology and direct force measurement of $\mathrm{WS}_{2}$ nested fullerene-like nanostructures.

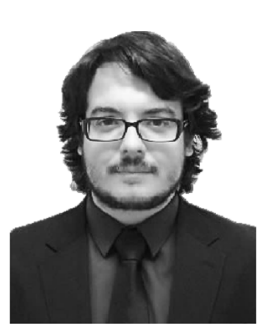

Ignacio TUDELA. He received his BEng degree (equivalent) in chemical engineering from the University of Alicante, Spain, in 2008. After that, he worked in different applied electrochemistry projects at the University of Alicante until 2011, when he joined Daido Metal's European Technical Centre UK as a materials researcher and $\mathrm{PhD}$ student in a joint project with Coventry University. After the

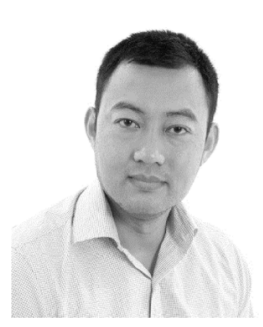

Yi ZHANG. He received his BEng degree in polymer materials from East China University of Science and Technology (ECUST) in 2002. He then received the MS degree in surface engineering from the University of Nottingham in 2003 and completed the $\mathrm{PhD}$ degree in materials engineering at Loughborough University in 2007. After the completion of his PhD degree, he joined Daido Metal
Adv Mater 11: 934-937 (1999)

[22] Rapoport L, Lvovsky M, Lapsker I, Leshinsky V, Volovik Y, Feldman Y, Zak A, Tenne R. Slow release of fullerene-like $\mathrm{WS}_{2}$ nanoparticles as a superior solid lubrication mechanism in composite matrices. Adv Eng Mater 3: 71-75 (2001)

[23] Rapoport L, Leshchinsky V, Lapsker I, Volovik Y, Nepomnyashchy O, Lvovsky M, Popovitz-Biro R, Feldman $\mathrm{Y}$, Tenne R. Tribological properties of $\mathrm{WS}_{2}$ nanoparticles under mixed lubrication. Wear 255: 785-793 (2003)

[24] Glaeser W A. Wear debris classification. In Modern Tribology Handbook. Bhushan B, Ed. Boca Raton-London-New YorkWashington DC: CRC Press, 2000.

[25] Sivandipoor I, Ashrafizadeh F. Synthesis and tribological behaviour of electroless Ni-P-WS ${ }_{2}$ composite coatings. Appl Surf Sci 263: 314-319 (2012)

[26] Ratoi M, Niste V B, Walker J, Zekonyte J. Mechanism of action of $\mathrm{WS}_{2}$ lubricant nanoadditives in high-pressure contacts. Tribol Lett 52: 81-91 (2013)

[27] Wang L, Gao Y, Xu T, Xue Q. A comparative study on the tribological behavior of nanocrystalline nickel and cobalt coatings correlated with grain size and phase structure. Mater Chem Phys 99: 96-103 (2006)

[28] Jeong D H, Gonzalez F, Palumbo G, Aust K T, Erb U. The effect of grain size on the wear properties of electrodeposited nanocrystalline nickel coatings. Scripta Mater 44: 493-499 (2001)

completion of his $\mathrm{PhD}$ degree, in 2015 he became senior materials researcher at Daido Metal's European Technical Centre UK, leading the Materials Research Team driving the development of novel material solutions and manufacturing processes for different tribological applications. His research interests cover a wide range of areas such as surface, coating and material's science \& engineering and manufacturing; tribology and mechanical engineering; chemistry, electrochemistry and chemical engineering.

Co. Ltd, European Technical Centre UK as a materials scientist in 2007, becoming principle materials scientist in 2013 leading the Materials Research Team in the UK. Since 2015, he is the Head of Research and Development within European Technical Centre UK, responsible for R\&D activities in the UK. His research interests cover a wide range of areas such as material science, surface engineering \& manufacturing, tribology, and mechanical engineering. 